\title{
Association between Helicobacter pylori seropositivity and mild to moderate COPD: clinical implications in an Asian country with a high prevalence of $H$. pylori
}

\author{
This article was published in the following Dove Press journal: \\ International Journal of COPD \\ 31 August 2016 \\ Number of times this article has been viewed
}

\author{
Ha Youn Lee ${ }^{1,2}$ \\ Ji Won Kim ${ }^{2,3}$ \\ Jung Kyu Lee 2,4 \\ Eun Young $\mathrm{Heo}^{2,4}$ \\ Hee Soon Chung ${ }^{2,4}$ \\ Deog Keom Kim ${ }^{2,4}$ \\ 'Division of Pulmonary and Critical \\ Care Medicine, Department of \\ Internal Medicine, Seoul National \\ University Hospital, ${ }^{2}$ Department of \\ Internal Medicine, Seoul National \\ University College of Medicine, \\ ${ }^{3}$ Division of Gastroenterology, \\ ${ }^{4}$ Division of Pulmonary and Critical \\ Care Medicine, Department of \\ Internal Medicine, Seoul National \\ University College of Medicine, Seoul \\ Metropolitan Government-Seoul \\ National University Boramae Medical \\ Center, Seoul, Republic of Korea
}

\begin{abstract}
Background: Helicobacter pylori infection is a major cause of gastric diseases. The clinical implications of $H$. pylori infection in various diseases outside the gastrointestinal system have also been reported, including in some respiratory disorders. In this study, we investigated the seroprevalence of $H$. pylori in patients with mild to moderate COPD in an Asian country with a high prevalence of $H$. pylori infection. Also, we aimed to elucidate the association between the seroprevalence of H. pylori and the decline of lung function in patients with COPD.
\end{abstract}

Methods: Participants who underwent a medical checkup for H. pylori at a referral hospital in Korea were recruited for this study. All participants were tested for H. pylori infection using an immunoassay of the $H$. pylori-specific immunoglobulin $\mathrm{G}(\mathrm{IgG})$ concentration and a rapid urease test at the time of endoscopy with a gastric mucosal specimen. We assessed the decline in lung function using the spirometric data of those who underwent spirometry more than three times.

Results: In total, 603 participants (201 patients with COPD and 402 controls) were analyzed. The seroprevalence of $H$. pylori $\operatorname{IgG}$ in the patients and controls was $45.8 \%$ and $52.2 \%$, respectively $(P=0.134)$. The H. pylori IgG level in patients with COPD was not significantly different from that of the controls (114.8 and 109.6 units/mL, respectively; $P=0.549$ ). In addition, there were no significant differences in the annual forced expiratory volume in 1 second or forced vital capacity between the participants with $H$. pylori seropositivity and seronegativity.

Conclusion: This study showed no relationship between H. pylori infection and COPD in a country with a high burden of $H$. pylori infection. Furthermore, H. pylori infection did not affect the rate of lung function decline in this study population.

Keywords: H. pylori, COPD, lung function decline

\section{Introduction}

Helicobacter pylori can be resistant to the acidic conditions of the stomach and colonizes the gastric epithelium by producing urease. ${ }^{1}$ This microorganism also causes gastric inflammation by various virulence factors such as vacuolating cytotoxin $\mathrm{A}$, cytotoxin-associated gene product $\mathrm{A}$, and neutrophil-activating protein $\mathrm{A} .{ }^{1,2}$ H. pylori infection is a major cause of gastric diseases such as chronic active gastritis, peptic ulcer disease, and mucosa-associated lymphoid tissue lymphoma. ${ }^{3-5}$ Infection with H. pylori can be detected by gastric mucosal biopsy, a rapid urease test, and simple serologic tests. Despite the limitations of serologic testing for H. pylori infection, this technique has been widely used because it is simple and noninvasive.
Correspondence: Deog Keom Kim Division of Pulmonary and Critical Care Medicine, Department of Internal Medicine, Seoul National University College of Medicine, Seoul Metropolitan Government-Seoul National University Boramae Medical Center, 20

Boramaero-5-Gil, Dongjak-Gu, Seoul

I56-707, Republic of Korea

$\mathrm{Tel}+8228702228$

Fax +8228312826

Email kimdkmd@snu.ac.kr 
Interestingly, $H$. pylori infection may not be restricted to the stomach. Since the first report that coronary heart disease might be associated with H. pylori seropositivity in $1994,{ }^{6}$ several studies on the implications of H. pylori infection in various diseases outside the gastrointestinal system have been published. Such systems include the cardiovascular, neurological, dermatological, immunological, hematological, hepatobiliary, ophthalmological, endocrinological, and gynecological systems. ${ }^{7-9}$

Until now, the extragastrointestinal implications of H. pylori infection have been hypothesized to be associated with systemic inflammation, which might in turn be associated with $H$. pylori-induced gastric inflammation. The chronic gastric inflammatory response induces systemic inflammation and immune responses by altering the polarized T-helper 1 and 2 responses. However, whether H. pyloriinduced inflammation plays a role in the pathogenesis of extragastric diseases remains unclear. ${ }^{10}$

An association between $H$. pylori infection and respiratory disease has recently been reported. ${ }^{11}$ Bronchiectasis, tuberculosis, and lung cancer are reportedly associated with higher $H$. pylori seroprevalence. ${ }^{12}$ However, several epidemiological studies have shown an inverse relationship between $H$. pylori infection and the incidence of allergic airway diseases including asthma. ${ }^{10,13,14} \mathrm{~A}$ few studies, including some with small study samples, have identified a potential association between $H$. pylori infection and COPD. The prevalence of $H$. pylori seropositivity was found to be higher in patients with COPD than in those without COPD..$^{15,16}$ Also, a significant relationship between $\mathrm{H}$. pylori seropositivity and the forced expiratory volume in 1 second $\left(\mathrm{FEV}_{1}\right)$ was recently demonstrated. ${ }^{17}$ However, considering that the prevalence of $\mathrm{H}$. pylori infection exhibits regional variability,$^{18}$ we suspected that the clinical impact of $H$. pylori infection on the prevalence of COPD and lung function may differ according to the regional prevalence of $H$. pylori. Nevertheless, until now, no reports have addressed the association between $H$. pylori infection and COPD and the impact of H. pylori infection on lung function in Asian countries with a high burden of H. pylori infection.

In this study, we aimed to elucidate the association between $H$. pylori infection and the presence of mild to moderate COPD in an Asian country with high prevalence of $H$. pylori infection. We also aimed to identify the impact of $\mathrm{H}$. pylori infection on declining lung function in patients with COPD.

\section{Methods Study population}

For this case-control study, we recruited participants aged $\geq 40$ years who underwent a medical checkup and serologic test for H. pylori at Seoul Metropolitan GovernmentSeoul National University Boramae Medical Center from January 2013 to February 2015. Routine checkups during the study period also included esophagogastroduodenoscopy (EGD), spirometry, and a basic demographic questionnaire.

The patients' information was obtained from the clinical records and anonymized prior to analysis. The Institutional Review Board of Seoul Metropolitan Government-Seoul National University Boramae Medical Center approved the study protocol (IRB No 16-2015-40/041) however informed consent was not sought as per IRB requirements with retrospective studies.

\section{Selection of cases and controls}

Among the participants who underwent a medical checkup and serology test for $H$. pylori, patients with mild to moderate COPD were selected as cases and participants without airflow limitation on spirometry were regarded as controls.

Mild to moderate COPD was defined as a prebronchodilator $\mathrm{FEV}_{1} /$ forced vital capacity $(\mathrm{FVC}$ ) ratio of $<0.7$ and $\mathrm{FEV}_{1}$ ( $\%$ predicted) of $\geq 50 \%$; patients with these values were assigned to the case group. Participants with an $\mathrm{FEV}_{1} /$ FVC ratio of $\geq 0.7$ were assigned to the control group. Age- and sex-matched controls were randomly selected at a control:case ratio of $2: 1$.

We excluded participants with allergic diseases such as asthma or allergic rhinitis as well as those with lung diseases that may contribute to airflow limitations such as lung cancer, pulmonary tuberculosis, and bronchiectasis involving more than one lobe.

The following clinical information was collected: age, sex, body mass index, comorbidities, smoking status, spirometric and laboratory data, radiographic findings, and EGD findings.

Among 236 patients with a defined airflow limitation, 35 patients were excluded as follows: 14 patients with asthma, eight patients with bronchiectasis involving more than one lobe, two patients with lungs destroyed by tuberculosis, one patient with empyema, four patients without available EGD data, five patients with severe COPD characterized by an $\mathrm{FEV}_{1}$ of $<50 \%$, and one patient without a matched control. Finally, 201 patients with mild to moderate COPD and their 402 matched controls were included in this analysis. 


\section{Measurements}

Seropositivity and rapid urease test for $H$. pylori infection

H. pylori-specific immunoglobulin $\mathrm{G}$ ( $\mathrm{IgG})$ concentrations were measured with a commercially available enzyme-linked immunosorbent assay (DIESSE Diagnostica Senese, Siena, Italy) according to the manufacturer's protocol. The lower limit of a positive $H$. pylori $\operatorname{IgG}$ titer was 20 units $/ \mathrm{mL}$. To determine the $H$. pylori infection status, a rapid urease test (CLO test; Ballard Medical Products, Draper, UT, USA) was performed at the time of endoscopy with a gastric mucosa specimen obtained by endoscopic biopsy. The CLO test was positive when the gel pellet turned dark pink to magenta color for up to 24 hours.

Spirometry and annual rate of lung function decline Spirometry was performed according to the criteria of the American Thoracic Society. ${ }^{19}$ The method described

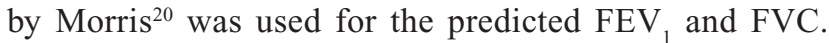
Prebronchodilator spirometry data were used for analysis because postbronchodilator testing is not performed in Korea. To assess the annual decline in lung function, we collected the participants' spirometry data if they had undergone spirometry more than three times per year since January 2010.

\section{Statistical analysis}

The chi-square test was used to compare categorical variables, a $t$-test was used to compare normally distributed continuous data, and the Wilcoxon rank sum test was used to compare non-normally distributed continuous variables. The associations between the $H$. pylori IgG level and various pulmonary function parameters were investigated using Pearson's correlation coefficient. Multivariable association analysis was performed with logistic regression analyses, adjusting for sex, age, smoking status, gastric diseases known to be related to H. pylori infection, and the severity of airflow limitation as defined by $\mathrm{FEV}_{1}$. Concordance between the CLO test result and $\operatorname{IgG}$ seropositivity for $H$. pylori infection was analyzed with the kappa index. Decline in FEV 1 or FVC over time was analyzed with random-slope, random-intercept mixed linear regression, adjusting for age, sex, body mass index, smoking status, and baseline FEV ${ }_{1}$ or FVC. All statistical analyses were performed using Statistical Package for the Social Sciences for Windows (version 22.0; IBM Corporation, Armonk, NY, USA) and Stata software (version 12.1; StataCorp LP, College Station, TX, USA).

\section{Results \\ Baseline characteristics of the study population}

In total, 603 participants (201 patients with COPD and 402 controls) were analyzed in this study. The baseline characteristics of the study population are listed in Table 1. The participants' mean age was 60 years, and most of them were men (87.1\%). The mean $\mathrm{FEV}_{1}$ of patients with COPD was $88.60 \% \pm 14.9 \%$ of predicted, and nonsmokers comprised $15.4 \%$ of all patients with COPD. Hypertension and diabetes were the most common comorbidities and were suggested to be associated with $H$. pylori infection. The prevalence rates of these suggested comorbidities were not significantly different between the cases and controls.

\section{H. pylori seropositivity and COPD}

As shown in Table 2, IgG seropositivity for H. pylori was present in about half the participants in each group without a significant difference (cases, $45.8 \%$; controls, $52.2 \%$; $P=0.13$ ). Also, in a quantitative comparison of the association between the IgG level of $H$. pylori and the presence of

Table I Baseline clinical characteristics of COPD patients and control group

\begin{tabular}{|c|c|c|c|}
\hline Characteristics & $\begin{array}{l}\text { COPD } \\
(n=201)\end{array}$ & $\begin{array}{l}\text { Control } \\
(n=402)\end{array}$ & $P$-value \\
\hline Age, years & $60.68 \pm 8.24$ & $60.68 \pm 8.23$ & \\
\hline Male (\%) & $175(87.1)$ & $350(87.1)$ & \\
\hline Body mass index, $\mathrm{kg} / \mathrm{m}^{2}$ & $24.07 \pm 3.02$ & $24.16 \pm 2.73$ & $0.685^{*}$ \\
\hline Height & $1.68 \pm 0.069$ & $1.67 \pm 0.069$ & $0.095^{*}$ \\
\hline Smoking status (\%) & & & $<0.001$ \\
\hline Current smoker & $73(36.3)$ & $86(21.4)$ & \\
\hline Exsmoker & $95(47.3)$ & $166(4 \mid .3)$ & \\
\hline Nonsmoker & $31(15.4)$ & I 44 (35.8) & \\
\hline Median pack-years (IQR) & $25(15.0-40.0)$ & $20.0(12.5-35.0)$ & 0.312 \\
\hline \multicolumn{4}{|l|}{ Spirometry } \\
\hline $\mathrm{FEV}_{\text {, }}$ & $2.58 \pm 0.59$ & $3.04 \pm 0.53$ & $<0.00 I^{*}$ \\
\hline $\mathrm{FEV}_{1}(\%)$ & $88.6 \pm 14.94$ & $106.0 \pm 13.02$ & $<0.001 *$ \\
\hline FVC & $3.91 \pm 0.812$ & $3.83 \pm 0.66$ & $0.241^{*}$ \\
\hline FVC (\%) & $96.8 \pm 13.52$ & $96.6 \pm 11.27$ & $0.833^{*}$ \\
\hline $\mathrm{FEV}_{1} / \mathrm{FVC}$ & $65.91 \pm 6.18$ & $79.45 \pm 5.13$ & $<0.00 I^{*}$ \\
\hline Hypertension (\%) & $59(29.4)$ & $121(30.1)$ & $0.850 * *$ \\
\hline Diabetes mellitus (\%) & $27(13.5)$ & $67(16.7)$ & $0.313 * *$ \\
\hline Chronic kidney disease (\%) & I $(0.5)$ & $10(2.5)$ & $0.111 * *$ \\
\hline Iron deficiency anemia (\%) & $0(0)$ & $2(0.5)$ & $0.555 * *$ \\
\hline Cardiovascular disease (\%) & & & $0.71 \mathrm{I} * *$ \\
\hline Coronary artery disease & $3(1.5)$ & $8(2.0)$ & \\
\hline Cerebrovascular disease & $2(1.0)$ & $2(0.5)$ & \\
\hline
\end{tabular}

Notes: Continuous data are shown as mean $\pm S D$, $* P$-value from $t$-test, ${ }^{*} * P$-value from Fisher's exact test.

Abbreviations: $\mathrm{FEV}_{1}$, forced expiratory volume in I second; FVC, forced vital capacity; IQR, interquartile range; SD, standard deviation. 
Table 2 The prevalence of positive Helicobacter pylori serology by COPD stage

\begin{tabular}{llll}
\hline & COPD $(\mathbf{n = 2 0 I})$ & Control $(\mathbf{n}=\mathbf{4 0 2})$ & P-value \\
\hline H. pylori lgG seropositivity $n(\%)$ & $92(45.8)$ & $210(52.2)$ & 0.134 \\
H. pylori lgG level, units/mL Median (IQR) & $114.8(33.6-191.0)$ & $109.6(34.3,166.4)$ & 0.549 \\
\hline
\end{tabular}

Notes: $* P$-value from chi-squared test, ${ }^{*} * P$-value from Mann-Whitney test.

Abbreviations: IgG, immunoglobulin G; IQR, interquartile range.

COPD, no significant difference was found between the two groups (cases, 114.8 units/mL; controls, 109.6 units/mL; $P=0.55$ ) (Table 2; Figure 1).

In a comparison of the concordance between $H$. pylori seropositivity and the CLO test results, 71 of 89 (79.8\%) with a positive CLO test result showed $H$. pylori seropositivity and 99 of 147 (67.3\%) patients with a negative CLO test result showed $H$. pylori seronegativity (kappa index, 0.442; $P<0.001$ ) (Table 3). The discordant fractions between the two tests were not different in either group (kappa index for cases, 0.407; kappa index for controls, $0.464 ; P<0.001$ for both) (Table 3$)$.

\section{H. pylori seropositivity and severity of air flow limitation}

When the airflow limitation $\left(\mathrm{FEV}_{1}\right)$ in patients with COPD was graded using the Global Initiative for Chronic Obstructive Lung Disease criteria, there was no significant difference in $H$. pylori seropositivity between patients with stage 1 and stage 2 COPD (46.1\% and 44.9\%, respectively; $P=0.89$ for all comparisons). In addition, no relationship between the serum level of IgG for $H$. pylori and $\mathrm{FEV}_{1}$ was found in the cases or controls, or among the entire study population (n=187, $r=-0.07, P>0.05)$ (Figure 2). Using an absolute value of $\mathrm{FEV}_{1}$, there was no relationship between the serum level of IgG for $H$. pylori and $\mathrm{FEV}_{1}(\mathrm{n}=187, r=-0.026$, $P=0.729$ ).

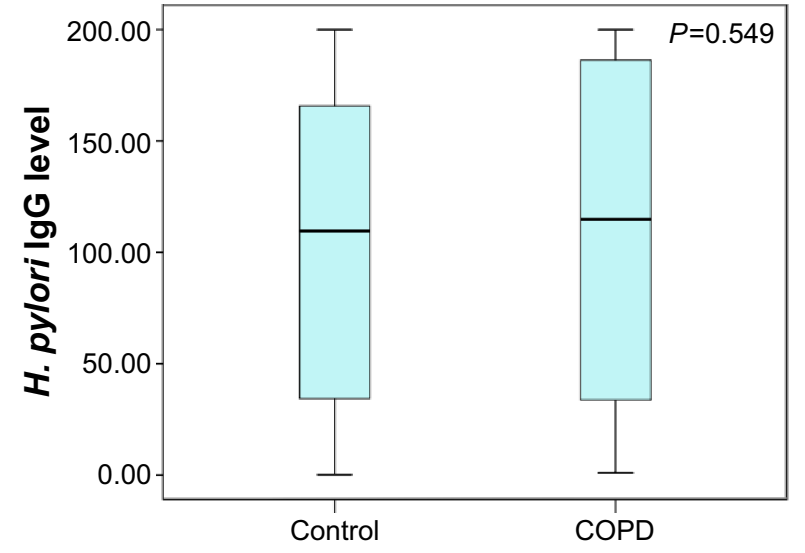

Figure I Helicobacter pylori serum IgG levels in COPD patients and control subjects. Note: Displayed as median $\pm \mathrm{IQR}$.

Abbreviations: $\lg G$, immunoglobulin G; IQR, interquartile range.

\section{Multivariate analysis of the association between $H$. pylori infection and COPD}

The presence of $H$. pylori infection was evaluated by seropositivity and the CLO test. Therefore, the association between H. pylori infection and COPD was tested with respect to seropositivity and the CLO test results.

The univariate analysis of associations with seropositivity revealed that smoking status, presence of cardiovascular disease, gastric diseases including gastritis and peptic ulcer disease, and COPD were not associated with H. pylori seropositivity, while gastroesophageal reflux disease (GERD) showed a significant negative association with $H$. pylori seropositivity (Table 4). After adjustment for smoking status, presence of cardiovascular disease, presence of endoscopic gastritis and peptic ulcers, and GERD, we found that COPD was not associated with $H$. pylori seropositivity in this analysis. Only GERD was negatively associated with $H$. pylori seropositivity.

A total of 232 (38.5\%) study participants underwent the CLO test because it was performed at the discretion of the endoscopist. Of these 232 patients, 89 (38.4\%) showed CLO positivity. The CLO test was not associated with COPD, smoking status, the presence of cardiovascular disease, or the presence of gastric disease. However, GERD tended to be associated with a lower rate of CLO positivity.

\section{Impact of $H$. pylori seropositivity on lung function decline}

A total of 195 participants (51 cases, 144 controls) underwent spirometry three or more times per year. Among them, 93 (47.7\%) exhibited H. pylori seropositivity. Because the final trends were not different between cases and controls, we assessed the association between $H$. pylori seropositivity and the decline in lung function in the total study population. Even in the whole study population, there was no difference

Table 3 The association of seropositivity of Helicobacter pylori and CLO tests

\begin{tabular}{lll}
\hline & $\begin{array}{l}\text { H. pylori } \\
\text { seropositive (I I 9) }\end{array}$ & $\begin{array}{l}\text { H. pylori } \\
\text { seronegative ( I 1 7) }\end{array}$ \\
\hline CLO positive patients (89) & 7I (79.8\%) & $18(20.2 \%)$ \\
CLO negative patients (147) & $48(32.7 \%)$ & $99(67.3 \%)$ \\
\hline
\end{tabular}

Notes: Kappa index: $0.442, P<0.001$. 


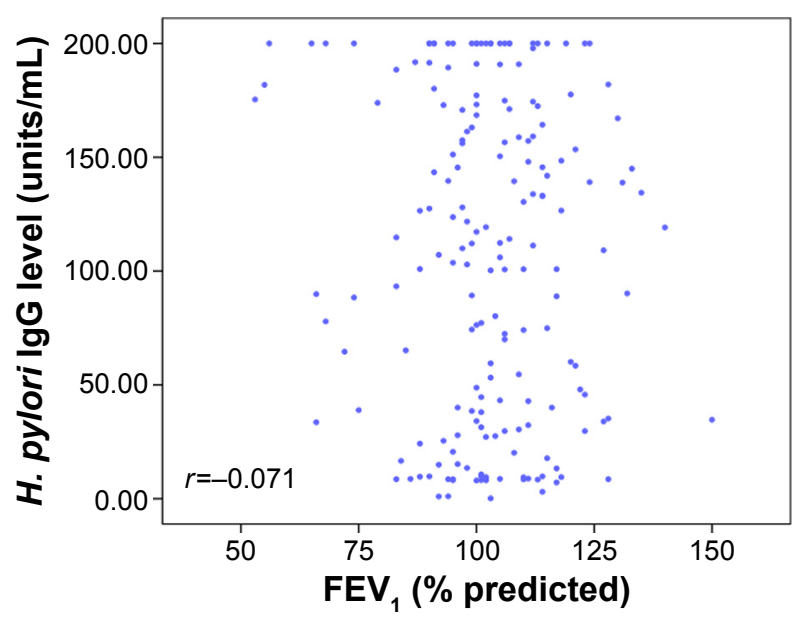

Figure 2 Correlation between Helicobacter pylo IgG titer and $\mathrm{FEV}$. Notes: The distribution of $H$. pylori IgG titer according to the airflow limitation. Linear regression of the $H$. pylori lgG versus FEV, (\%). No significant correlation was found between two variables ( $n=|87, r=-0.07|, P=0.333$ ).

Abbreviations: $\mathrm{FEV}_{1}$, forced expiratory volume in I second; IgG, immunoglobulin G.

in the annual rate of decline in the $\mathrm{FEV}_{1}$ between the H. pylori-seropositive and -seronegative groups (7.8 6.8 and $6.8 \pm 6.6 \mathrm{~mL} /$ year, respectively; $P=0.92$ ) (Table 5; Figure 3). Similarly, the annual rate of decline in the FVC was not different between the $H$. pylori-seropositive and -seronegative groups (28.9 \pm 8.7 and $27.4 \pm 8.5 \mathrm{~mL} /$ year, respectively; $P=0.90$ ).

\section{Discussion}

The seroprevalence of $H$. pylori among patients with COPD was not different from that of healthy controls in this study. Also, H. pylori seropositivity did not accelerate the annual rate of lung function decline during the 3-year follow-up period. This indicates that the seroprevalence of $H$. pylori might not be associated with the incidence and progression of COPD in countries with a high burden of $H$. pylori infection. Our results regarding lung function decline are consistent with a recent large cohort study that demonstrated no difference in the annual rate of lung function decline between seropositive and seronegative individuals. ${ }^{17}$
Although a few studies have suggested a cross-sectional relationship between $H$. pylori seroprevalence and COPD, there is no definitive evidence of a causal pathophysiologic association between H. pylori and COPD. Moreover, compared to the two previous studies, our study included relatively healthy patients because we used data from participants in an annual health screening program. GERD and cigarette smoking have been suggested as important confounding factors that explain this inconsistent seroprevalence in patients with COPD. As in the present study, many epidemiological studies have demonstrated a negative association between $H$. pylori infection and GERD. ${ }^{21,22}$ However, according to the epidemiologic reports of COPD, GERD is one of the most common comorbidities in patients with COPD, especially advanced-stage COPD. ${ }^{23,24}$ This inverse relationship among COPD, GERD, and $H$. pylori infection is related to the inconsistent seroprevalence of $H$. pylori in patients with COPD. Nevertheless, because only patients with mild to moderate COPD were recruited in this study, the impact of COPD severity on the prevalence of GERD and $H$. pylori infection may be minimal.

Cigarette smoking might also have an ambivalent influence on the association between COPD and H. pylori infection. Smoking is a major risk factor for the development of COPD, but whether H. pylori infection is associated with smoking remains unclear. Both higher and lower seropositivity of $H$. pylori have been reported in smokers compared with nonsmokers. ${ }^{25-28}$

Seropositivity was relatively high in the present study (up to half of the patients with COPD), similar to the general population of Korea. ${ }^{29,30}$ Therefore, H. pylori infection is so common that it may have only a modest effect on the incidence and disease progression of COPD in countries with a high burden of $H$. pylori infection, even if it is a real contributor.

Another point should be considered when interpreting the results of studies on the seroprevalence of H. pylori and its

Table 4 Univariate and multivariate analysis of Helicobacter pylori seropositivity

\begin{tabular}{|c|c|c|c|c|c|c|c|c|}
\hline \multirow[t]{2}{*}{ Variables } & \multicolumn{4}{|l|}{ Seropositivity } & \multicolumn{4}{|l|}{ CLO positivity } \\
\hline & $\begin{array}{l}\text { Unadjusted } \\
\text { OR }(95 \% \mathrm{Cl})\end{array}$ & $P$-value & $\begin{array}{l}\text { Adjusted } \\
\text { OR }(95 \% \mathrm{Cl})\end{array}$ & $P$-value & $\begin{array}{l}\text { Unadjusted } \\
\text { OR (95\% CI) }\end{array}$ & $P$-value & $\begin{array}{l}\text { Adjusted } \\
\text { OR }(95 \% \mathrm{Cl})\end{array}$ & $P$-value \\
\hline Smoking & $0.857(0.602-1.220)$ & 0.391 & $0.909(0.630-1.313)$ & 0.612 & $1.304(0.668-2.544)$ & 0.464 & $1.296(0.647-2.596)$ & 0.464 \\
\hline CVD & $1.510(0.531-4.297)$ & 0.440 & $1.340(0.467-3.845)$ & 0.586 & $0.99 I(0.23 I-4.250)$ & 0.990 & $0.900(0.208-3.899)$ & 0.888 \\
\hline Gastritis/peptic ulcer & I.343 (0.76I-2.37I) & 0.309 & I.I 32 (0.629-2.037) & 0.679 & $4.4(0.532-36.372)$ & 0.169 & $3.961(0.468-33.519)$ & 0.207 \\
\hline GERD & $0.482(0.322-0.721)$ & $<0.001$ & $0.485(0.321-0.733)$ & 0.001 & $0.494(0.241-1.013)$ & 0.054 & $0.527(0.254-|.09|)$ & 0.084 \\
\hline COPD & $0.772(0.550-1.084)$ & 0.135 & $0.778(0.546-\mathrm{I} .108)$ & 0.164 & I.023 (0.597-I.755) & 0.933 & $1.014(0.577-1.78 \mid)$ & 0.963 \\
\hline
\end{tabular}

Note: $P$-value from multiple logistic regression analysis, adjusting for sex, age, smoking status, gastric diseases known to be related to $H$. pylori infection, and the severity of airflow limitation as defined by FEV,

Abbreviations: $\mathrm{Cl}$, confidence interval; GERD, gastroesophageal reflux disease; OR, odds ratio; CVD, cardiovascular disease. 
Table $\mathbf{5}$ Impact of Helicobacter pylori test on the lung function decline

\begin{tabular}{llll}
\hline Total (195) & $\begin{array}{l}\text { H. pylori } \\
\text { seropositive (93) }\end{array}$ & $\begin{array}{l}\text { H. pylori } \\
\text { seronegative (102) }\end{array}$ & P-value \\
\hline FEV , (SE) & $7.8 \mathrm{~mL} /$ year (6.8) & $6.8 \mathrm{~mL} /$ year (6.6) & 0.92 \\
FVC (SE) & $28.9 \mathrm{~mL} /$ year (8.7) & $27.4 \mathrm{~mL} /$ year (8.5) & 0.90 \\
\hline
\end{tabular}

Note: Adjusted by age, sex, BMI, initial FEV , or FVC, smoking status. Abbreviations: BMI, body mass index; $\mathrm{FEV}_{\mathrm{l}}$, forced expiratory volume in I second; FVC, forced vital capacity; SE, standard error.

extragastric manifestations, that is, the limitations of seropositivity testing for $H$. pylori infection. As shown in this study, there is a discrepancy between the serum H. pylori IgG level and the CLO test results. Although serum H. pylori IgG measurement is a clinically useful noninvasive diagnostic test for $\mathrm{H}$. pylori infection, some studies have shown that it has lower accuracy than the $13 \mathrm{C}$ urea breath test and exhibits disagreement with the histopathological findings (kappa statistic, 0.72 ; accuracy, $86 \%)^{31-33}$

This study has some strengths in terms of investigating the role of $H$. pylori in patients with COPD. First, to the best of our knowledge, this is the first report on the association between $H$. pylori seroprevalence and the prevalence of COPD, and between H. pylori seroprevalence and annual lung function decline in a country with a high burden of H. pylori infection. Also, because the study population was recruited from among individuals who participated in an annual health screening program and were thought to be relatively healthy, the participants' characteristics are considered to be very similar to those of the Korean general population with respect to the prevalence of diseases such as diabetes mellitus and hypertension, despite the fact that the study population was small. ${ }^{34,35}$ Furthermore, the H. pylori seropositivity rate was similar to that in previous reports on Korean populations. ${ }^{29,30,36}$ This indicates that our study population was minimally affected by selection bias.

Second, this study focused on patients with mild to moderate COPD. In patients with advanced COPD, GERD is a common comorbidity and may be associated with lung hyperinflation, increased abdominal pressure, and a high rate of medical treatment for COPD. ${ }^{37}$ Therefore, in patients with advanced COPD, the actual association between $H$. pylori infection and COPD may be affected by GERD. This suggests that the present study may provide more reliable data regarding the association between $H$. pylori seroprevalence and COPD.

Third, we tested the participants for H. pylori infection using both the CLO test and serologic tests. Our results were consistent using both methods, indicating that the data of this study are reliable.

Despite these merits and interesting results, this study had some limitations. First, the study design prevented evaluation of additional contributing factors related to the causal role of H. pylori in the pathogenesis of COPD. Second, the small sample size may be an obstacle to generalize the results to the general population. Third, the follow-up period may have been too short to fully elucidate the rate of decline in lung function, and we could not evaluate the change in the annual decline in lung function after $H$. pylori eradication. Although 3 years may be a rather short period, we thought it was possible to identify a rapid or slower decline even with a 3-year follow-up period. Moreover, there is uncertainty regarding $H$. pylori infection at the first $\mathrm{FEV}_{1}$ measurement, even though we used spirometry data within a couple of years from the time the serology test was performed. Finally, the effects of respiratory medications
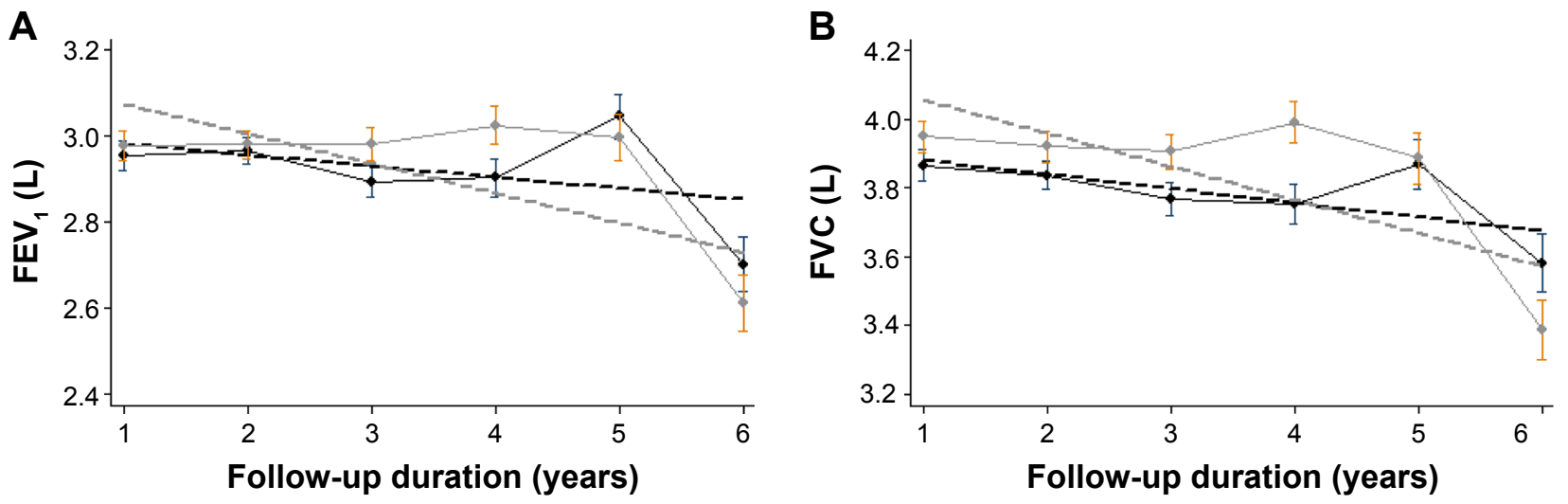

$$
\bullet \text { H. pylori Seronegative } \multimap H . \text { pylori Seropositive }
$$

Figure 3 Impact of Helicobacter pylori seropositivity on lung function decline.

Notes: (A) FEV, decline and (B) FVC decline.

Abbreviations: $\mathrm{FEV}_{\text {, }}$, forced expiratory volume in I second; FVC, forced vital capacity. 
on the decline in lung function were not considered because we could not verify the use of respiratory medications.

In conclusion, this study demonstrated no association between $H$. pylori infection and mild to moderate COPD in a country with a high burden of $H$. pylori infection. Furthermore, $H$. pylori infection did not affect the rate of decline in lung function in this study population.

\section{Author contributions}

DKK designed and coordinated the study. HYL performed the data analysis and drafted the manuscript. JWK participated in interpretation of the data. JKL, EYH, and HSC contributed to acquire these data and helped with reviewing the study and the manuscript. All authors contributed toward data analysis, drafting and revising the paper and agree to be accountable for all aspects of the work.

\section{Disclosure}

The authors report no conflicts of interest in this work.

\section{References}

1. Malfertheiner P, Link A, Selgrad M. Helicobacter pylori: perspectives and time trends. Nat Rev Gastroenterol Hepatol. 2014;11(10):628-638.

2. Salama NR, Hartung ML, Müller A. Life in the human stomach: persistence strategies of the bacterial pathogen Helicobacter pylori. Nat Rev Microbiol. 2013;11(6):385-399.

3. Marshall B, Warren JR. Unidentified curved bacilli in the stomach of patients with gastritis and peptic ulceration. Lancet. 1984;323(8390): 1311-1315.

4. Wotherspoon A, Ortiz-Hidalgo C, Falzon M, Isaacson P. Helicobacter pylori-associated gastritis and primary B-cell gastric lymphoma. Lancet. 1991;338(8776): 1175-1176

5. Malfertheiner P, Chan FK, McColl KE. Peptic ulcer disease. Lancet. 2009;374(9699):1449-1461

6. Mendall MA, Goggin PM, Molineaux N, et al. Relation of Helicobacter pylori infection and coronary heart disease. Br Heart J. 1994; 71(5):437-439.

7. Banić M, Franceschi F, Babić Z, Gasbarrini A. Extragastric manifestations of Helicobacter pylori infection. Helicobacter. 2012;17(Suppl 1): $49-55$.

8. Franceschi F, Gasbarrini A. Helicobacter pylori and extragastric diseases. Best Practice Res Clin Gastroenterol. 2007;21(2):325-334.

9. Franceschi F, Tortora A, Gasbarrini G, Gasbarrini A. Helicobacter pylori and extragastric diseases. Helicobacter. 2014;19(Suppl 1):52-58.

10. Reibman J, Marmor M, Filner J, et al. Asthma is inversely associated with Helicobacter pylori status in an urban population. PLoS One. 2008; 3(12):e4060.

11. Kanbay M, Kanbay A, Boyacioglu S. Helicobacter pylori infection as a possible risk factor for respiratory system disease: a review of the literature. Respir Med. 2007;101(2):203-209.

12. Zhuo WL, Zhu B, Xiang ZL, Zhuo XL, Cai L, Chen ZT. Assessment of the relationship between Helicobacter pylori and lung cancer: a meta-analysis. Arch Med Res. 2009;40(5):406-410.

13. Arnold IC, Dehzad N, Reuter S, et al. Helicobacter pylori infection prevents allergic asthma in mouse models through the induction of regulatory T cells. J Clin Invest. 2011;121(8):3088-3093.

14. Fullerton D, Britton JR, Lewis SA, Pavord ID, McKeever TM, Fogarty AW. Helicobacter pylori and lung function, asthma, atopy and allergic disease - a population-based cross-sectional study in adults Int J Epidemiol. 2009;38(2):419-426.
15. Siva R, Birring SS, Berry M, Rowbottom A, Pavord ID. Peptic ulceration, Helicobacter pylori seropositivity and chronic obstructive pulmonary disease. Respirology. 2013;18(4):728-731.

16. Gencer M, Ceylan E, Yildız Zeyrek F, Aksoy N. Helicobacter pylori seroprevalence in patients with chronic obstructive pulmonary disease and its relation to pulmonary function tests. Respiration. 2007;74(2): $170-175$.

17. Sze MA, Chen YW, Tam S, et al. The relationship between Helicobacter pylori seropositivity and COPD. Thorax. 2015;70(10):923-929.

18. Mentis A, Lehours P, Mégraud F. Epidemiology and diagnosis of Helicobacter pylori infection. Helicobacter. 2015;20(Suppl 1):1-7.

19. Miller M, Hankinson J, Brusasco V, et al. Standardization of spirometry, 1994 update. American Thoracic Society. Am J Respir Crit Care Med. 1995;152(3):1107-1136.

20. Morris JF. Spirometry in the evaluation of pulmonary function. West J Med. 1976;125(2):110.

21. Delaney B, McColl K. Review article: Helicobacter pylori and gastrooesophageal reflux disease. Aliment Pharmacol Ther. 2005;22(Suppl 1): $32-40$.

22. Raghunath A, Hungin APS, Wooff D, Childs S. Prevalence of Helicobacter pylori in patients with gastro-oesophageal reflux disease: systematic review. BMJ. 2003;326(7392):737.

23. Kempainen RR, SavikK, Whelan TP, DunitzJM, HerringtonCS,Billings JL. High prevalence of proximal and distal gastroesophageal reflux disease in advanced COPD. Chest. 2007;131(6):1666-1671.

24. Lee AL, Goldstein RS. Gastroesophageal reflux disease in COPD: links and risks. Int J Chron Obstruct Pulmon Dis. 2015;10:1935-1949.

25. Hishida A, Matsuo K, Goto Y, et al. Smoking behavior and risk of Helicobacter pylori infection, gastric atrophy and gastric cancer in Japanese. Asian Pac J Cancer Prev. 2010;11(3):669-673.

26. Ogihara A, Kikuchi S, Hasegawa A, et al. Relationship between Helicobacter pylori infection and smoking and drinking habits. J Gastroenterol Hepatol. 2000;15(3):271-276.

27. Parasher G, Eastwood GL. Smoking and peptic ulcer in the Helicobacter pylori era. Eur J Gastroenterol Hepatol. 2000;12(8):843-853.

28. Brenner H, Rothenbacher D, Bode G, Adler G. Relation of smoking and alcohol and coffee consumption to active Helicobacter pylori infection: cross sectional study. BMJ. 1997;315(7121):1489-1492.

29. Yim JY, Kim N, Choi SH, et al. Seroprevalence of Helicobacter pylori in South Korea. Helicobacter. 2007;12(4):333-340.

30. Lim SH, Kwon J-W, Kim N, et al. Prevalence and risk factors of Helicobacter pylori infection in Korea: nationwide multicenter study over 13 years. BMC Gastroenterol. 2013;13(1):104.

31. Pilotto A, Franceschi M, Leandro G, et al. Noninvasive diagnosis of Helicobacter pylori infection in older subjects comparison of the 13Curea breath test with serology. J Gerontol A Biol Sci Med Sci. 2000;55(3): M163-M167.

32. Yakoob J, Abbas Z. Agreement between serology and histology for detection of Helicobacter pylori infection. J Coll Physicians Surg Pak. 2014;24(10):779-780.

33. Mahmood S, Hamid A. Comparison between invasive and noninvasive tests in diagnosis of Helicobacter pylori infection. Pak J Biol Sci. 2010;13(10):509-512.

34. Kim NR, Kim HC. Prevalence and trends of isolated systolic hypertension among Korean adults: the Korea National Health and Nutrition Examination Survey, 1998-2012. Korean Circ J. 2015;45(6): 492-499.

35. Korean Diabetes Association. Korean Diabetes Fact Sheet; 2015. Available from: http://www.diabetes.or.kr/temp/KDA_fact_sheet $\% 20$ 2015.pdf. Accessed on January 6, 2016.

36. Kim JH, Kim HY, Kim NY, et al. Seroepidemiological study of Helicobacter pylori infection in asymptomatic people in South Korea. J Gastroenterol Hepatol. 2001;16(9):969-975.

37. Casanova C, Baudet J, del Valle Velasco M, et al. Increased gastrooesophageal reflux disease in patients with severe COPD. Eur Respir J. 2004;23(6):841-845. 


\section{Publish your work in this journal}

The International Journal of COPD is an international, peer-reviewed journal of therapeutics and pharmacology focusing on concise rapid reporting of clinical studies and reviews in COPD. Special focus is given to the pathophysiological processes underlying the disease, intervention programs, patient focused education, and self management protocols.

This journal is indexed on PubMed Central, MedLine and CAS. The manuscript management system is completely online and includes a very quick and fair peer-review system, which is all easy to use. Visit http://www.dovepress.com/testimonials.php to read real quotes from published authors.

Submit your manuscript here: http://www.dovepress.com/international-journal-of-chronic-obstructive-pulmonary-disease-journal 